\title{
Training of Engineering Professionals in Higher Education as Economic Development Factor
}

\author{
Vladimir Demidov \\ Associate Professor of the Department of Criminal Law and \\ Criminal Procedure of the Graduate School of Law and \\ Forensic Technical Expertise \\ Peter the Great St. Petersburg Polytechnic University \\ S-Petersburg, Russia
}

\author{
Dmitriy Mokhorov \\ Associate Professor, Director of the Graduate School of \\ Law and Forensic Technical Expertise \\ Peter the Great St. Petersburg Polytechnic University \\ S-Petersburg, Russia \\ mokhorov@mail.ru
}

\author{
Anna Mokhorova \\ Associate Professor of the Graduate School of International Relations \\ Peter the Great St. Petersburg Polytechnic University \\ S-Petersburg, Russia \\ mokhorova@list.ru
}

\begin{abstract}
In this day and age, economic growth challenges have proven the objective need to gradually improve the training system of technical and information professionals to provide states with labor forces in order to ensure progress in addressing social and economic aspects of raising living standards. Different states implement various programs aimed at improving the training of professionals in higher education establishments. The present study considers the latest education trends in the training of professionals. The study incorporated the comparative law method, the statistical method, the social analysis method and the economic modelling method to analyze the education processes. The listed methods presented the objective aspects of higher engineering education in various areas of human activity. The comparative law method was used to analyze legal regulation models in higher education used by different universities. The statistical method was used to assess the efficiency of certain education provision approaches based on a significant amount of data. The obtained findings showed that the quality of training in higher engineering education is currently one of the primary factors that directly impact the technological progress rate in every state. The value of engineering knowledge for humanity development is constantly growing as information and technical processes required for further social and economic growth become more complicated and complex. The preparation of specialists in higher education institutions is believed to be a key factor that determines the success of states in the most advanced areas of human knowledge.
\end{abstract}

Keywords: engineering education, higher education, economic growth, education system, areas of pedagogical activity, higher engineering education

\section{INTRODUCTION}

The training of engineering specialists is important for every country in the world that seeks to achieve high social and economic growth rates and gradually address the issue of transforming the primary sectors of the national economy. As technical and technological processes today often change their direction, it results in the pressing need to quickly transform the higher education system in order to overcome economic challenges. Therefore, the necessity to align the level of higher engineering education with the problems the society is currently faced with becomes of utmost importance. The education system might be improved in various ways, which explains the numerous research approaches to the issue. As many experts highlighted in their works, rapid changes in different aspects of the economic activity demand even more rapid development of the engineering knowledge. However, the qualification of trained engineers often fails to meet the standards necessary to address challenges emerging in the human development. As a result, many universities try to implement a wide range of various approaches aimed at ensuring acquirement of new engineering knowledge in order to help maintain the required economic growth rate. Many experts have different opinions regarding current activities of higher education establishments; yet, there are some radical approaches that have already been introduced into education processes $[1,2,3]$. Some experts point out the need to reform engineering education as "the task of higher education is to educate students to become effective modern engineers", which is not realized today to a required extent [4, p.2]. Others highlight inconsistency of contemporary engineering education as "on the one hand, practice-oriented institutions 
have turned to more science-oriented curricula; on the other hand, universities whose traditional mission is to deliver research-based knowledge have developed profession-oriented curricula" [5 p.71].

Some studies analyze various methods of knowledge transfer in the contemporary engineering common for leading higher education establishments in the most developed countries in the world [6]. According to some researchers, such methods as problem-based learning [7, pp. 7-12], distance learning [8, pp. 236-241], business simulation games [9, pp. 429-437], active learning [10] and others have a remarkably positive impact on the quality of training of engineering students and ensure that the acquired knowledge corresponds to the current state of engineering.

Besides, legal regulations are proven to have a positive influence on the higher education realization due to strict specified requirements for results of education, as well as the state policy regarding the establishment of a human resource pool and its role in the economic growth of the country.

\section{PURPOSE OF THE STUdY}

The present study analyzes the impact of various factors on the training of engineering specialists who are essential for ensuring a better economic growth rate of the country in today's world.

\section{RESEARCH METHODS}

The study was based on comparative law methods used to evaluate the impact level of legal regulation imposed by the state and education establishments on improvement of engineering education. A social analysis of contemporary teaching forms in institutions of technology was conducted, and economic modelling methods were applied to provide clear evidence of the best approaches that could be implemented in order to achieve a high level of training the graduates.

Moreover, the outcome of the prepared professionals addressing the challenges facing the state was studied in the framework of the statistical method.

\section{FINDINGS AND DISCUSSION}

Many aspects of the teaching activity determine factors that influence the preparation of engineering specialists in numerous higher education institutions all over the world. These factors reflect the potential of human society to ensure the successful preparation of specialists involved in different stages of the technical and technological progress, which is particularly relevant to states seeking to maintain their economic growth rate, as it stimulates the overall progress of the society in the economic sector and brings new significant scientific knowledge.

Engineering specialists are capable of introducing innovations into technological aspects of production processes in which considerable amounts of goods are manufactured to meet the needs of citizens in various countries. Moreover, they can apply their professional training and expertise to help introduce technological innovations into those sectors that experience an urgent need to update their technological and engineering facilities. However, these tasks may remain unsolved if the quality of preparing engineering specialists is not aligned with the technological development of today`s world. It may also result in a rapid decline in efficiency of new technologies used in different economic sectors. This explains why many people believe the education processes in many engineering universities to be clearly flowed as they are based on outdated methods of teaching that fail to prove their efficiency in the preparation of engineering specialists. It should also be mentioned that the teaching quality of engineering students is adversely affected by the lack of modern equipment and an insufficient information environment in many engineering universities [11].

The following educational processes influence the preparation of modern professionals: educational curriculum adequacy; comprehensive theoretical and applied knowledge within a specific academic discipline; academic qualifications of higher-education teaching personnel.

Any educational curriculum is based on legal acts of the State and local acts of educational institutions. Monitoring of the (curriculum) implementation provides efficiency of the educational process. Academic staff qualifications are closely connected with specific academic courses' content as a subjective factor. Therefore, the academic staff is to develop their professional skills in order to provide would-be engineering specialists with up-to-date knowledge on a regular basis in the context of their training. A great number of universities offer on-the-job training for their academic personnel. A high level of professional skill can only be achieved through the constant continuing professional development of the teaching staff. In order to provide comprehensive academic staff retraining and maintain a high level of the educational process in the context of engineering sciences, the majority of universities obtain specialized expertise of both internal and external leading scientists.

The level of engineering specialists' preparation directly depends on the combination of the theoretical and practical knowledge within a particular curriculum, which in turn reflects development of various sectors of human economic activities of the XXI century. The constant efforts of the higher-education teaching personnel to master knowledge in the field of cutting-edge technologies, innovative methods and techniques of transformation of industries in the national economy allows the faculty involved in training of engineering specialists to educate engineering professionalsto-be.

We consider engineering education as an organized continuing educational process aimed at preparing and nurturing would-be engineering specialists. Such education is to result in development of the engineering mindset that will allow future specialists to not only operate the most sophisticated equipment but also design up-to-date machinery and mechanisms. Development of the engineering mindset is one of the main elements of specialists' training without which inventive activity and innovation would be impossible [ ]. Implementation of various organizing forms and models in 
order to increase engineering students' creative activity is vital when training highly qualified professional. Business incubators which are regarded as small enterprises within an education institution can be considered a good example of such an approach. Students have an opportunity to put their ideas into practice in conditions close to the market economy requirements. Future professionals also acquire the skills necessary for organizing small-scale venture companies. It is well-known that a lot of successful mass-produced innovative gadgets and devices are tested in such small-scale companies where engineering graduates and students are deeply involved.

The establishment of the state scientific and research institutions also benefits the training of engineering specialists. A great number of highly-qualified specialists in such organizations provide opportunities for breakthroughs in the process of scientific and technological advancement, as well as to achieve successful implementation of the newest machinery and materials. Such a process deeply influences development of cutting-edge scientific and industrial sectors.

Networking among education institutions and industrial enterprises (especially the most advanced ones) has a great impact on the efficiency of the engineering professionals' training. A networking system is a relevant one, as engineering universities focus on requirements when training future professionals. Thus, higher education institutions satisfy the need for formation of the engineering elite in order to solve practical tasks that enterprises and unions engaged in the production of technically complex goods and samples of the newest devices face.

It is worth noting that the level of engineering specialists' preparation is becoming the key factors of national competitiveness. The success of the social and economic policy of the State, implementation of the most significant society development programs and achievement of highquality life depend on the professionals' qualifications.

There are several factors which negatively impact preparation and educational process of the engineering professionals necessary for successful development of all branches of the national economy based on the tasks that are relevant at the present time. They should be pointed out in the context of the educational system's role in the development of the national economy.

The lack of comprehensiveness in the preparation of engineering higher-education institutions' students is one of those significant negative factors. This shortcoming can be seen in the fact that the engineers-to-be do not obtain comprehensive knowledge of a specific field material production during their education. Instead they receive a rather narrow set of skills that allows them to achieve some initial success in their work, and then becomes an obstacle to adoption of new patterns in technology and technological progress. As engineering professions are not viewed as prestigious ones, it affects the educational process in engineering universities in a negative way. Surely, it is not common in every developed country, but some of them do have a tendency to favor liberal arts.
The aging of scientific and academic staff as well as the insufficient inflow of young specialists also negatively affect the system of higher engineering education. Obviously, it is widely accepted that famous scientists and researchers determine the level of advancement of cutting-edge engineering thought in specific areas of the research. However, it is quite common for engineering universities to retain quite a senior academic staff involved in the training and teaching process. As young specialists are more interested in pursuing better financial opportunities with leading corporations and organizations, they are not willing to replace the members of the senior academic staff despite having the potential to do so.

In order to ensure the consistent development of the technical sphere of the society, it is necessary for the engineering universities' graduates to have a well-developed engineering mindset aimed at creative problem-solving in the context of new technical tools and new technologies creation. It allows the specialists to see the entire problem from different angles and identify connections within.

The lack of the truly formed engineering mindset among engineering graduates is due to the fact that many higher education institutions have so far used outdated training programs related to certain areas of the professional activity. Nevertheless, a significant disadvantage that affects development of specific approaches that would allow wouldbe specialists to solve the given problem is implementation of outdated teaching methods within engineering universities. Hence it can be explained by a significant gap between sets of the theoretical knowledge, exact methods and their implementation in everyday activities of engineering professionals [12].

\section{CONCLUSION}

The above-mentioned factors of preparing specialists in the field of engineering knowledge in universities of technology actually affect development of various industries in the economy of each country. Insufficient preparation of specialists working in the engineering field of the economy has a negative effect on renovating processes of the technological sphere and on workforce productivity in leading industries of the economy. If universities of technology are not able to ensure preparation of a necessary number of engineering specialists, this has a significant negative effect on rates of the economic growth, as it is impossible to ensure a steady socio-economic growth in any country without adoption of new technology and technological processes. A preparation level of engineering specialists has a direct influence on the pace, at which the society can adopt and apply the scientific achievements characterizing the country development.

Primarily, the process of preparing engineering specialists is determined by a level of professional educational activity at universities of technology. Successful preparation of highquality specialists for particular industries of the economy is related to research and technological facilities of higher education institutions, and subsidies of educational processes by the state. The higher these indicators are, the more effective 
[4] E.F. Crawley, J. Malmqvist, S.Östlund, D.R Brodeur, K. Edström, "Rethinking Engineering Education", The CDIO, vol. 2, 2014.

solutions can be provided by universities to prepare top specialists, who would be in demand in a variety of countries to ensure the socio-economic development of the society. Apart from this, preparation of engineering specialists is influenced by the quality of teaching special engineering subjects by a particular university. It is worth noting that professional knowledge of engineering university graduates depends on application of brand-new methods and techniques by the lecturing and teaching staff, which is based on using high technology.

The level of professional preparation is mostly determined by consistency of the approaches to the educational activity undertaken by many universities of technology. Actual learning outcomes and preparation of engineering specialists are reflected by the economic growth rates in a particular country. The better preparation a university of technology provides, the higher probability that the society will be able to perceive innovations in the field of technology, which will ensure a steady progress.

\section{REFERENCES}

[1] E.D. Justo, A. Delgado, "Change to competence-based education in structural engineering", J. Prof. Issues Eng. Educ. Pract, vol. 141, 2015, pp.1-8.

[2] G.E. Veselov, N.A. Lyz, A.E. Lyz, "Building the Future: A Phased Approach to Improving Engineering Education", Higher Education in Russia, vol. 5(212), 2017, pp. 15-22.

[3] V.M. Zhurakovskyi, M.Yu.Baryshnikova, A.B. Vorov, Modernization of Engineering Education: Russian Trends and Modern Innovations [in Rus.]", Tomsk State University Journal, vol. 416, 2017, pp. 87-93. DOI: $10.17223 / 15617793 / 416 / 13$
[5] B. Delahousse, W. Bomke, "Structural Transformations in Higher Engineering (Chapter) /Education in Europe International Perspectives on Engineering Education", Engineering Education and Practice in Context, vol. 1, 2015.

[6] M.E. Auer, K.S. Kim, "Engineering Education for a Smart Society", World Engineering Education Forum \& Global Engineering Deans Council, 2016.

[7] A.L. Andersen, T.D. Brunoe, K. Nielsen, "Engineering Education in Changeable and Reconfigurable Manufacturing", Using Problem-Based Learning in a Learning Factory Environment Procedia CIRP, vol. 81, 2019.

[8] Zh. Lei, H. Zhou, W.Hu, "Combining MOOL with MOOC to Promote Control Engineering Education", Experience with NCSLab IFACPapersOnLine, vol. 52(9), 2019.

[9] M. Severengiz, I. Roeder, K. Schindler, G. Seliger, "Influence of Gaming Elements on Summative Assessment in Engineering Education for Sustainable Manufacturing", Procedia Manufacturing, vol. 21, 2018.

[10] R.M Lima, P.H. Andersson, E. Saalman, "Active learning in engineering education: A (re)introduction", Eur. J. Eng. Educ, vol. 42, 2017, pp. 1-4.

[11] I.D. Belousova, Features of information technological support of higher

[12] Education institution https://scholar.google.ru/scholar?hl=ru\&as sdt=0\%2C5\&q=\%D0\%BD $\% \mathrm{D} 0 \% \mathrm{~B} 5 \% \mathrm{D} 0 \% \mathrm{~B} 4 \% \mathrm{D} 0 \% \mathrm{BE} \% \mathrm{D} 1 \% 81 \% \mathrm{D} 1 \% 82 \% \mathrm{D} 0 \% \mathrm{~B} 0 \% \mathrm{D} 1 \% 82 \%$ D0\%BE\%D1\%87\%D0\%BD\%D0\%BE\%D1\%81\%D1\%82\%D0\%B8+\% D0\%B8\%D0\%BD\%D1\%84\%D0\%BE\%D1\%80\%D0\%BC\%D0\%B0\% D1\%86\%D0\%B8\%D0\%BE\%D0\%BD\%D0\%BD\%D0\%BE\%D0\%B3\% D0\%BE+\%D0\%BE\%D0\%B1\%D0\%B5\%D1\%81\%D0\%BF\%D0\%B5\% D1\%87\%D0\%B5\%D0\%BD\%D0\%B8\%D1\%8F+\%D1\%83\%D1\%87\% D0\%B5\%D0\%B1\%D0\%BD\%D1\%8B\%D1\%85+\%D0\%BF\%D1\%80\% D0\%BE\%D1\%86\%D0\%B5\%D1\%81\%D1\%81\%D0\%BE\&btnG=

[13] D.A.Mokhorov, A.Yu.Mokhorova, V.P Demidov, Legal education of students as one of the foundations of the formation of a modern civil society in the Russian Federation [in Rus.], vol. 10, 2019, pp. 142-14. 